\title{
Selenium status in vegans and lactovegetarians
}

\author{
BY B. AKESSON AND P. A. ÖCKERMAN \\ Department of Clinical Chemistry, University Hospital, Lund, Sweden
}

(Received 2 July 1984 - Accepted 10 October 1984)

\begin{abstract}
1. Plasma and urinary selenium were determined among vegans, lactovegetarians and several groups of omnivorous subjects, using gas-liquid chromatography.

2. Plasma Se was lower among lactovegetarians $(0 \cdot 80$ (SD $0 \cdot 18) \mu \mathrm{mol} / 1)$ than in the other groups $(0.98$ (SD $0 \cdot 15)$ $\mu \mathrm{mol} / 1)$. This was not related to Se intake, since the vegans had a lower and the lactovegetarians a higher intake of Se than omnivorous subjects in Sweden.

3. Urinary Se was $0 \cdot 36(\mathrm{SD} 0 \cdot 10) \mu \mathrm{mol} / \mathrm{d}$ for controls, $0 \cdot 17(\mathrm{SD} 0 \cdot 10) \mu \mathrm{mol} / \mathrm{d}$ for vegans and $0 \cdot 16(\mathrm{SD} 0 \cdot 07) \mu \mathrm{mol} / \mathrm{d}$ for lactovegetarians. No relation between dietary Se and urinary Se was observed. Among vegetarians, plasma Se and urinary Se were correlated $(r 0.51 ; P<0.05)$.
\end{abstract}

The amount of selenium in soil and thereby in food varies greatly between countries and also within some countries (Thomson \& Robinson, 1980; Yang et al. 1983). In Sweden the soil has a low Se content, like several other parts of northern Europe. It has been estimated that fish and meat are important sources of dietary Se in northern Europe and Se contents have been thoroughly documented for Finnish food (Varo \& Koivistoinen, 1980). Vegetarians may therefore run the risk of consuming too little Se. From previous studies it emerged that vegans consumed $0.014 \mu \mathrm{mol} \mathrm{Se} / \mathrm{MJ}(0.06 \mu \mathrm{mol} / \mathrm{Mcal})$ (Abdulla et al. 1981), lactovegetarians $0.091 \mu \mathrm{mol} / \mathrm{MJ}(0.38 \mu \mathrm{mol} / \mathrm{Mcal})$ (Abdulla et al. 1984) and omnivorous subjects $0.053 \mu \mathrm{mol} / \mathrm{MJ}(0 \cdot 22 \mu \mathrm{mol} / \mathrm{Mcal})$ (Borgström et al. 1979). To investigate whether the different Se intakes affected Se status in these subjects we have measured plasma Se concentration and urinary Se excretion using a sensitive gas-liquid chromatographic method.

\section{METHODS}

\section{Subjects}

(1) Vegans. Five healthy men and five healthy women were studied while staying at a vegan centre as described previously (Abdulla et al. 1981). Six of these subjects took part in the study on dietary intake (Abdulla et al. 1981). During that study, plasma, using heparin as anticoagulant, and a $24 \mathrm{~h}$ urine sample were collected.

(2) Lactovegetarians. Eleven women and twelve men stayed at the lactovegetarian centre as described elsewhere (Abdulla et al. 1984). Six of the subjects participated in the study on dietary intake. Plasma Se was determined in all subjects. Urinary Se was measured in seven subjects (four $24 \mathrm{~h}$ portions for each subject).

Three control groups of adults, apparently consuming common Swedish diets, were studied: (3) twenty-nine 78-year-old subjects (fifteen males and fourteen females) from a population characterized in detail previously (Borgström et al. 1979) were included in the first group; (4) laboratory personnel, 20-60 years $(n 12)$ comprised the second control group; (5) twenty apparently healthy blood donors were the third control group. Plasma Se was measured in all control subjects. Eighteen 24-h urine samples from control subjects were analysed. Student's $t$ test was used for the calculation of differences between groups. 


\section{Analytical methods}

Se was determined by a modification of the method described by McCarthy et al. (1981). Plasma $(0.2 \mathrm{ml})$ or urine $(0.5-1.0 \mathrm{ml})$ samples were transferred to disposable glass vials with flat bottoms (diameter $20 \mathrm{~mm}$, height $40 \mathrm{~mm}$ ). After the addition of $1.5 \mathrm{ml} 1.17 \mathrm{M}$-magnesium nitrate in concentrated nitric acid, the vials were heated on a hot plate at $105^{\circ}$ for $60 \mathrm{~min}$. The temperature was then increased in several steps and the vials were kept at $200^{\circ}$ until all the fluid had evaporated. The vials were then heated in a sand-bath at $450^{\circ}$ for $30 \mathrm{~min}$ and then in an oven at $500^{\circ}$ for $60 \mathrm{~min}$. Concentrated hydrochloric acid $(1.5 \mathrm{ml})$ was added and the vials were kept at $85^{\circ}$ for $15 \mathrm{~min}$. Then $2.5 \mathrm{ml}$ of a solution containing $2.5 \mathrm{M}$-urea, $61 \mathrm{~mm}$-hydroxylamine sulphate and $27 \mathrm{mM}$-disodium EDTA was added, and the samples were left at room temperature for $10 \mathrm{~min}$. 4-Nitro- $o$-phenylendiamine reagent $(0 \cdot 1 \mathrm{ml}, 5 \mathrm{~g} / 1$ $1 \mathrm{M}-\mathrm{HCl}$ ), prepared according to McCarthy et al. (1981), was added and the samples were left at $45^{\circ}$ for $30 \mathrm{~min}$. Toluene $(0.5-1.0 \mathrm{ml})$ was added and the samples were shaken and then left for phase separation for $10 \mathrm{~min}$. The upper phase was aspirated into tubes with ground-glass stoppers and stored at $-20^{\circ}$ until analysed.

Portions $(4 \mu \mathrm{l})$ of the samples were analysed by gas-liquid chromatography using a $1.8 \mathrm{~m} \times 2 \mathrm{~mm}$ i.d. glass column packed with $3 \%$ OV-225 on 100/120 mesh Gas-Chrom Q. A Sigma 3B instrument equipped with a ${ }^{63} \mathrm{Ni}$ electron capture detector and a Sigma 15 Chromatography Data Station (Perkin-Elmer) were used. The oven temperature was $180^{\circ}$ and the detector temperature was $350^{\circ}$. Nitrogen of high purity was used as carrier gas. The flow-rate was $30 \mathrm{ml} / \mathrm{min}$ and through the detector the total gas-flow was $60 \mathrm{ml} / \mathrm{min}$. The piazselenol peak was assessed quantitatively by peak area or peak height measurement.

Elemental Se dissolved in $\mathrm{HNO}_{3}(50 \mathrm{ml} / \mathrm{l})$ was used as standard (Fig. 1). The validity of the method was checked by analysing Standard Reference Material 1577, bovine liver, National Bureau of Standards. The given value was 1.1 (SD 0.1) $\mu \mathrm{g} \mathrm{Se} / \mathrm{g}$ and we found 1.08 (sD 0.06) $\mu \mathrm{g} / \mathrm{g}(n 14)$. The coefficient of variance when duplicate samples were analysed was $3.7 \%$.

\section{RESULTS}

Concentrations of Se in plasma are shown in Table 1. For vegans (mean $0.94 \mu \mathrm{mol} / \mathrm{l}$ ) the values did not differ significantly from those in any other group. Lactovegetarians (mean $0.80 \mu \mathrm{mol} / \mathrm{l})$ had lower values than the elderly and the laboratory personnel control groups $(P<0.001)$. Plasma Se was the same in all groups of subjects on a normal diet, calculated using one-way analysis of variance. Since this applied also to the elderly group, no influence of age could be observed. Plasma Se was the same in men and women. The mean value for all three control groups was 0.98 (SD 0.15) $\mu \mathrm{mol} / \mathrm{l}$.

The mean urinary excretion of Se among controls was $0.36 \mu \mathrm{mol} / \mathrm{d}$ (Table 1). The excretion was significantly lower among vegans (mean $0.17 \mu \mathrm{mol} / \mathrm{d}$ ) and lactovegetarians (mean $0.16 \mu \mathrm{mol} / \mathrm{d} ; P<0.001$ ). The inter-individual variation was marked in all groups.

For the lactovegetarians, urine samples from four consecutive days were analysed (Fig. 2). Each individual had a constant day-to-day excretion. For the vegans, and most lactovegetarians, plasma and urine samples had been obtained on the same day and therefore we studied the relation between plasma concentration and urinary excretion (Fig. 3). There was a weakly-positive correlation $(P<0.05)$ for the whole group.

\section{DISCUSSION}

The present values for plasma Se in Swedish subjects (range 0.66-1.39 (mean 0.98) $\mu \mathrm{mol} / \mathrm{l}$ ) for all control subjects ( $n$ 61) are consistent with values for blood Se presented previously for Swedish subjects (Brune et al. 1966). Table 2 shows that subjects in several other 


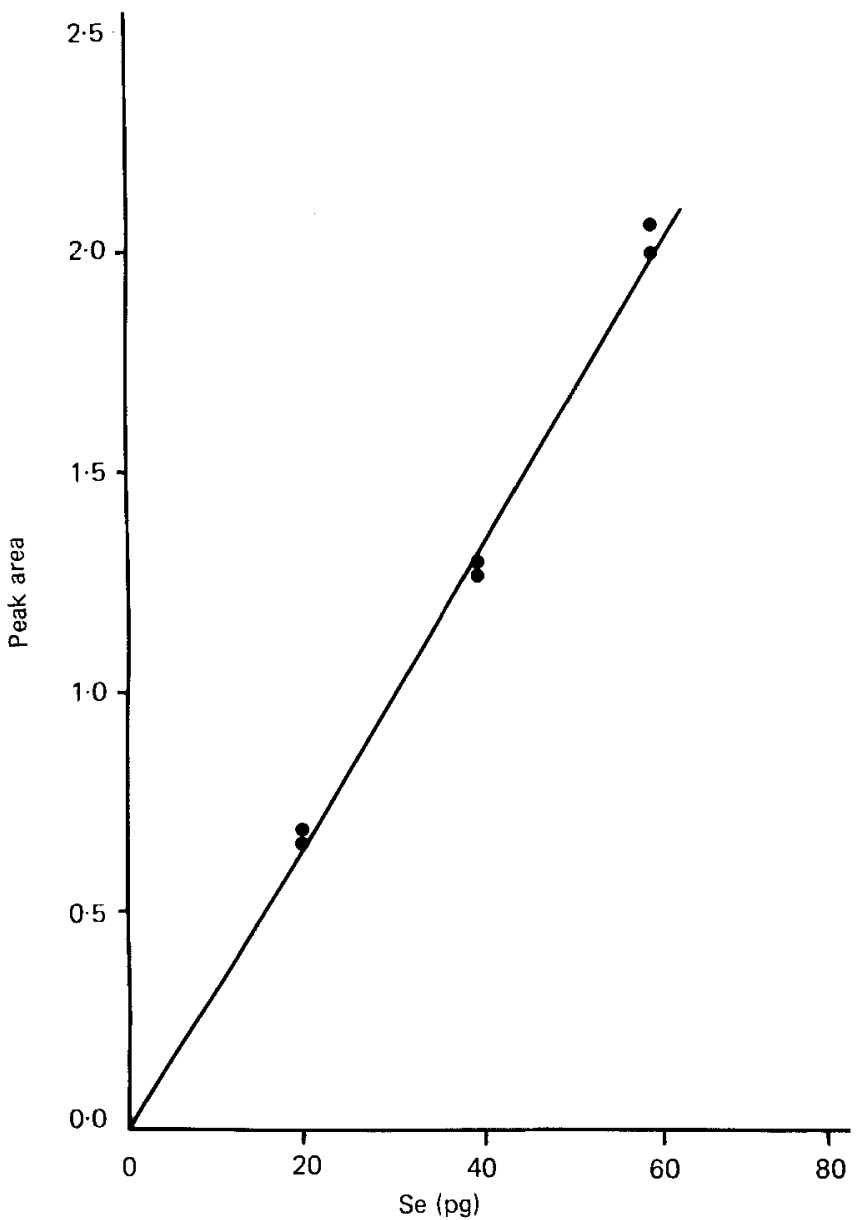

Fig. 1. Determination of selenium (pg) by gas-liquid chromatography. Different amounts of Se standard were processed as described on p. 200. The values on the $x$ axis represent the amounts of Se injected into the gas-liquid chromatograph.

Table 1. Plasma selenium $(\mu \mathrm{mol} / \mathrm{l})$ and urinary Se $(\mu \mathrm{mol} / \mathrm{d})$ in different subjects

\begin{tabular}{|c|c|c|c|c|}
\hline \multirow[b]{2}{*}{ Group of subjects } & \multicolumn{2}{|c|}{$\begin{array}{c}\text { Plasma Se } \\
(\mu \mathrm{mol} / 1)\end{array}$} & \multicolumn{2}{|c|}{$\begin{array}{c}\text { Urinary Se } \\
(\mu \mathrm{mol} / \mathrm{d})\end{array}$} \\
\hline & Mean & SD & Mean & SD \\
\hline Vegans & 0.94 & 0.24 & $0 \cdot 17 \dagger$ & $0 \cdot 10$ \\
\hline Lactovegetarians & $0 \cdot 80^{*}$ & $0 \cdot 18$ & $0 \cdot 16 \dagger$ & 0.07 \\
\hline \multicolumn{5}{|l|}{ Controls } \\
\hline Elderly & 0.99 & $0 \cdot 11$ & - & - \\
\hline Blood donors & 0.94 & $0 \cdot 19$ & - & - \\
\hline Laboratory personnel & $1 \cdot 04$ & 0.15 & $0 \cdot 36$ & $0 \cdot 10$ \\
\hline
\end{tabular}

* Mean values were significantly different from those of the elderly and the laboratory personnel control groups $(P<0.001)$.

$\dagger$ Mean values were significantly different from those of the laboratory personnel control group $(P<0.001)$. 


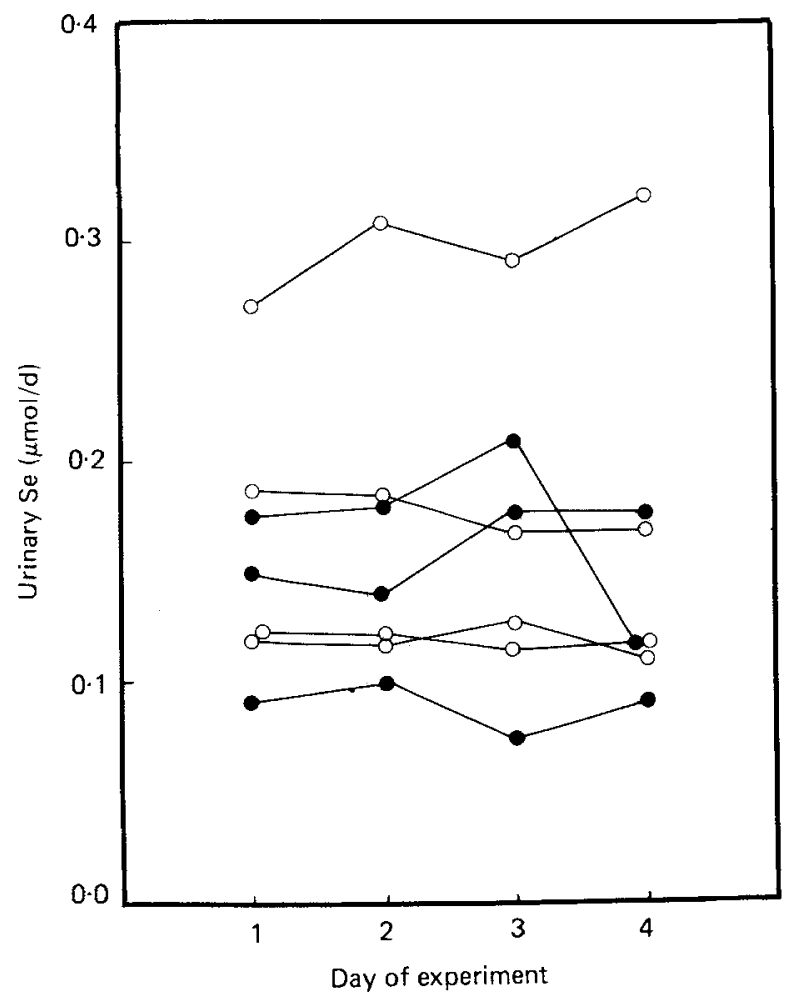

Fig. 2. Urinary excretion of selenium $(\mu \mathrm{mol} / \mathrm{d})$ among seven lactovegetarians on four consecutive days. (O), Men; (O), women.

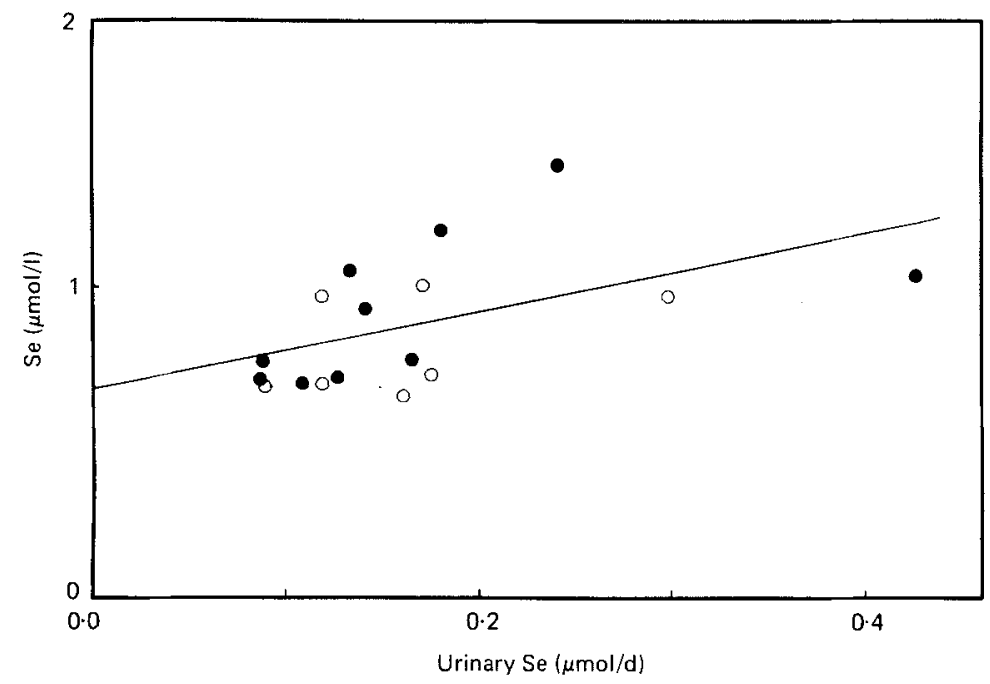

Fig. 3. Relation between plasma selenium $(\mu \mathrm{mol} / 1)$ and urinary Se excretion $(\mu \mathrm{mol} / \mathrm{d})$ among vegans (O) and lactovegetarians $(O) . r 0 \cdot 51$. 
Table 2. Plasma concentration of selenium among healthy adults in different countries

(Mean values and standard deviations)

\begin{tabular}{|c|c|c|c|c|c|}
\hline \multirow[b]{3}{*}{ Country } & \multicolumn{4}{|c|}{ Plasma Se } & \multirow[b]{3}{*}{ Reference } \\
\hline & \multicolumn{2}{|c|}{$\mu \mathrm{mol} / 1$} & \multicolumn{2}{|c|}{$\mu \mathrm{g} / 1$} & \\
\hline & Mean & SD & Mean & $\mathrm{SD}$ & \\
\hline Norway & 1.53 & 0.25 & 121 & 20 & Aaseth et al. (1982) \\
\hline USA & 1.52 & 0.13 & 120 & 10 & Sullivan et al. (1979) \\
\hline Denmark & $1 \cdot 23$ & 0.18 & 97 & 14 & Egeskov-Jensen $e t a l .(1980)$ \\
\hline Belgium & $1 \cdot 23$ & $0 \cdot 15$ & 97 & 12 & Verlinden et al. (1983) \\
\hline Italy & $1 \cdot 00$ & 0.04 & 79 & 3 & Calautti et al. (1980) \\
\hline Sweden & 0.98 & 0.15 & 77 & 12 & Present study \\
\hline \multirow[t]{3}{*}{ Finland } & 1.05 & 0.20 & 83 & 16 & Salonen et al. (1982) \\
\hline & 0.70 & $0 \cdot 19$ & 55 & 15 & Välimäki et al. (1983) \\
\hline & $0.53-1 \cdot 37^{*}$ & & $42-108 *$ & & Westermarck et al. (1977) \\
\hline New Zealand & $0 \cdot 38$ & 0.13 & 30 & 10 & Rea et al. (1979) \\
\hline
\end{tabular}

* Range of means from adults in different parts of Finland.

European countries have similar Se levels. From the USA, higher concentrations, and from New Zealand and some parts of Finland, lower plasma Se concentrations, have been reported. In some areas in China, low-blood Se concentrations have been found (Yang et al. 1983). The variations may to some extent reflect differences in analytical methodology, although a recent collaborative study indicated reasonable agreement between most methods and laboratories (M. Ihnat, M. Wolynetz, Y. Thomassen \& M. Verlinden, unpublished results). The present study is the first one where gas-liquid chromatography with electron-capture detection has been used for plasma Se analysis in a clinical material. A major advantage of the method is its high sensitivity, permitting analysis of $0.1-0.2 \mathrm{ml}$ plasma. It has a good validity and acceptable precision.

Among the five groups studied the lactovegetarians had somewhat lower plasma Se than the different control groups. Thus no relation between dietary Se intake and plasma Se was evident, since results from previous studies by our group indicated that vegans consume less Se and lactovegetarians more Se than an omnivorous group (Fig. 4). Our findings agree with the recent report that blood Se of Seventh-Day Adventist vegetarians in the USA did not differ from that of non-vegetarians (Shultz \& Leklem, 1983).

Epidemiological studies have shown that the intake of Se has a major influence on Se in blood (Schrauzer \& White, 1978; Thomson \& Robinson, 1980) but other factors may also influence plasma Se, such as plasma protein turnover. Urinary Se may therefore be a more convenient indicator of Se status than plasma Se. Large differences in urinary Se excretion were recently reported for Chinese subjects with quite different Se intakes (Yang et al. 1983). In addition, urinary Se will change after a few days after an altered Se intake (Levander et al. 1981). Our results (Table 1) indicate that both vegans and lactovegetarians had a clearly lower urinary Se than that of the control groups. The mean excretion among vegetarians $(0.16 \mu \mathrm{mol} / \mathrm{d})$ is very close to that found for four women in New Zealand consuming $24 \mu \mathrm{g} \mathrm{Se} / \mathrm{d}(0.30 \mu \mathrm{mol} / \mathrm{d}$; Stewart et al. 1978). Valentine et al. (1978) found that urinary Se was better correlated to Se in drinking-water than was blood Se, which is in accordance with our findings.

The reason why urinary Se in the present study was not correlated to the simultaneous dietary intake of Se remains unclear. It may be due to variations in the availability of dietary $\mathrm{Se}$ and in Se excretion via other routes than urine. This strengthens the need for further studies on Se status in individuals on different dietary regimens. 


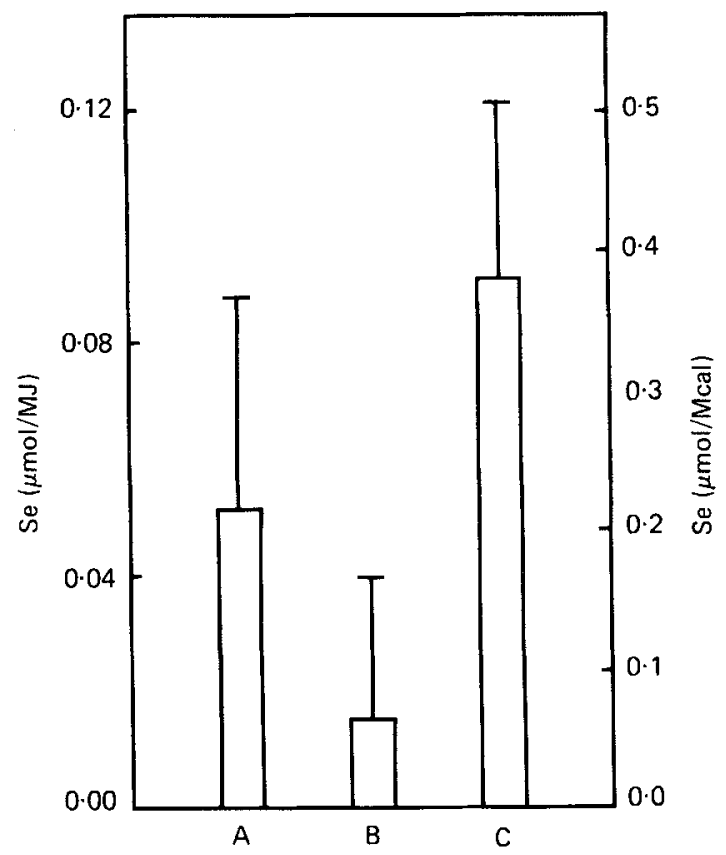

Fig. 4. Dietary intake of selenium ( $\mu \mathrm{mol} / \mathrm{MJ}$ and $\mu \mathrm{mol} / \mathrm{Mcal}$ ) by (A) omnivorous subjects, (B) vegans and $(C)$ lactovegetarians. The median intakes determined by analysis of duplicate portions were taken from previous publications (Borgström et al. 1979; Abdulla et al. 1981, 1984). The analyses were performed by Mr. K. Kolar using atomic absorption spectrophotometry.

This investigation was supported by grants from the Swedish Medical Research Council (Project 3968), A. Påhlsson's Foundation and Ekhaga Foundation. Skilful assistance was given by Ms B. Mårtensson and Mr J. Wijkander. The authors thank Dr $\AA$ Nordén for making some of the plasma samples available.

\section{REFERENCES}

Aaseth, J., Alexander, J., Thomassen, Y., Blomboff, J. P. \& Skrede, S. (1982). Clinical Biochemistry 15, $281-283$.

Abdulla, M., Aly, K.-O., Andersson, I., Asp, N.-G., Birkhed, D., Denker, I., Johansson, C.-G., Jägerstad, M., Kolar, K., Nair, B. M., Nilsson-Ehle, P., Nordén, Å., Rassner, S., Svensson, S., Åkesson, B. \& Ö́ckerman, P.-A. (1984). American Journal of Clinical Nutrition 40, 325-338.

Abdulla, M., Andersson, I., Asp, N.-G., Berthelsen, K., Birkhed, D., Dencker, I., Johansson, C.-G., Jägerstad, M., Kolar, K., Nair, B. M., Nilsson-Ehle, P., Nordén, Å., Rassner, S., Åkesson, B. \& Öckerman, P.-A. (1981). American Journal of Clinical Nutrition 34, $2464-2477$.

Borgström, B., Nordén, Å., Åkesson, B., Abdulla, M. \& Jägerstad, M. (1979). Scandinavian Journal of Gastroenterology 14, Suppl. 52.

Brune, D., Samsahl, K. \& Wester, P. O. (1966). Clinica Chimica Acta 13, 285-291.

Calautti, P., Moschini, G., Stievano, B. M., Tomio, L., Calzavara, F. \& Perona, G. (1980). Scandinavian Journal of Haematology 24, 53-66.

Egeskov-Jensen, G., Gissel-Nielsen, G. \& Clausen, J. (1980). Journal of the Neurological Sciences 48, 61-67.

Levander, O. A., Sutherland, B., Morris, W. C. \& King, J. C. (1981). American Journal of Clinical Nutrition 34, 2662-2669.

McCarthy, T. P., Brodie, B., Milner, J. A. \& Bevill, R. F. (1981). Journal of Chromatography 225, 9-16.

Rea, H. M., Thomson, C. D., Campbell, D. R. \& Robinson, M. F. (1979). British Journal of Nutrition 42, $201-208$. Salonen, J. T., Alfthan, G., Huttunen, J. K., Pikkarainen, J. \& Puska, P. (1982). Lancet ii, 175-179.

Schrauzer, G. N. \& White, D. A. (1978). Bioinorganic Chemistry 8, 303-318.

Shultz, T. D. \& Leklem, J. E. (1983). American Journal of Clinical Nutrition 37, 114-118. 
Stewart, R. D. H., Griffiths, N. M., Thomson, C. D. \& Robinson, M. F. (1978). British Journal of Nutrition 40, 45-54.

Sullivan, J. F., Blotcky, A. J., Jetton, M. M., Hahn, H. K. \& Burch, R. E. (1979). Journal of Nutrition 109, $1432-1437$.

Thomson, C. D. \& Robinson, M. F. (1980). American Journal of Clinical Nutrition 33, 303-323.

Valentine, J. L., Kang, H. K. \& Spivey, G. H. (1978). Environmental Research 17, 347-355.

Välimäki, M. J., Harju, K. J. \& Ylikahri, R. H. (1983). Clinica Chimica Acıa 130, 291-296.

Varo, P. \& Koivistoinen, P. (1980). Acta Agriculture Scandinavica 22, Suppl. 165-171.

Verlinden, M., van Sprundel, M., Van der Auwera, J. C. \& Eylentosch, W. J. (1983). Biological Trace Element Research 5, 91-102.

Westermarck, T., Raunu, P., Kirjarinta, M. \& Lappalainen, L. (1977). Acta Pharmacologica et Toxicologica 40 , $465-475$.

Yang, G., Wang, S, Zhou, R. \& Sun, S. (1983). American Journal of Clinical Nutrition 37, 872-881. 